\title{
Transactional Analysis Would Be Useful For Various Situations In Psychotherapy
}

\author{
Hiroshi Bando* \\ Tokushima University/Medical Research, Japan
}

*Corresponding author: Hiroshi Bando, Tokushima University/ Medical Research, Nakashowa 1-61, Tokushima 770-0943, Japan, Tel: +81-90-3187-

2485; Fax: +81-88-603-1030; Email: pianomed@bronze.ocn.ne.jp

Submission: 眥 May 05, 2018; Published: 眥 May 15, 2018

Abbreviations: CP: Critical Parent; NP: Nurturing Parent; TEG: Tokyo University Egogram; BMI: Body Mass Index; AC: Adapted Child; FC: Free Child; ICT: Information, Communication and Technology

\section{Commentary}

In recent years, lifestyle has been changing drastically with the spread of ICT and the change of social structure in the world. As a result, everyone was exposed to various stressors, and the number of people suffering from physical and mental disorders has increased. Therefore, the role of psychology, psychiatry and psychosomatic medicine has been practiced and expected for treatment and care of lots of people. There are a variety of factors influencing to these situation. Among them, the personality trait of each person has been important and necessary to be investigated. Research on personality and communication with other people would be meaningful, leading to healthier daily life and successful long life. Transactional Analysis is a personality theory advocated in the 1950s by American psychiatrist Eric Burne [1].

Based on psychoanalysis, it is a psychotherapy that incorporates human psychology, changes mind/behavior and encourages growth. The foundation of the way of thinking is that we cannot change the past nor other people as we think. It is important not to change the past and others, but to change the tendency of one's personality and the way of thinking. Then, you can break out of your thoughts and build a smooth human relationship. Furthermore, its aim would be the affirmation of self and others, in which I am OK and you are OK. Berne has advocated the PAC model. This hypothesis is that everyone has three ego states in the spirit, which are $\mathrm{P}$ (Parent), A (Adult), C (Child) formed during the experience of childhood. Based on exchange analysis, egogram has been developed by John M. Dusey, an American psychiatrist and psychologist [2].

Using egogram, five egos and the strength of each factor were investigated. From obtained results, we can derive personality trait in subjects. The relationship of the classification and definition of egos are explained in the following. When Berne originated 3 principal ego states, these characteristics were defined. They are
Child, Parent, and Adult. In addition, elaboration of ego theory made the two functional Parent ego, which is Critical and Nurturing. Similarly, two functional Child egos were made as Free and Adapted. CP stands for Critical Parent, with criticizing and regulating characteristics. NP means Nurturing Parent, for permitting and encouraging characteristics. A is Adult, focusing on gathering facts and considering alternatives and being objective. FC means Free Child, having self-orientation and optimistic characteristics. AC stands for Adapted Child, with restraining one's emotions and with social characteristics.

In the investigation of egogram, firstly, the state of the human ego is analyzed from five aspects. Then, it becomes clear which part is strong and what part is weak. After checking the result, summarizing the data into a graph form in an easy-to-understand manner would be egogram. The advantages of egogram are shown below. First, by knowing yourself, you will learn how to deal with self-control. Next, communication with people having different ego states can be smooth. Thirdly, it can connect to each selfactualization while maintaining harmony with daily life at families, schools, society, without losing its own likeness.

Egogram's research has been applied and used mainly as Tokyo University Egogram (TEG) for years. TEG is a highly reliable psychological examination based on transactional analysis, coming to know the tendency of personal character. As clinical research, several studies were found. In university hospital obesity clinic, 147 cases of obesity were on weight reduction program of 6 months [3]. The results included $6.2 \mathrm{~kg}$ weight reduction on average and 2.4 reductions in BMI. On the egogram study before and after trial, significant increases of A and FC were found, which seemed to be related to their self-monitoring skill and autonomy, respectively. The author and colleagues investigated 664 cases related to music therapy, and clarified that musical experience helps the 
optimization of egogram on the occasion of music therapy or a music session [4]. Moreover, there were related studies on obesity, anorexia, frequent hospitalization history, atopic dermatitis and so on [5-7]. These are also included in the category of psychosomatic disorders. Consequently, it is considered that the investigation of the relationship with egogram greatly contributes to future diagnosis and treatment.

Actually, it has been widely used not only in medical institutions but also in companies and schools. By getting personal tendency, it is possible to understand in advance the bias in thinking and susceptibility to mental illness. Everyone has different own personality and way of thinking, which is of course OK. If it is just too biased and any symptoms are found in the heart and body, gradually improving the cause and phenomenon is necessary. For that purpose, the result must be given to the person by the feedback, and the characteristics of human relations and way of thinking must be analyzed. Under these circumstances, TEG has been useful for better treatment and building better human relationships.

As it is actually easy to study the egogram questionnaire for each subject, it can be done in about 5-10 minutes. At first, each subject is to check the questionnaire and measure five ego states. Subsequently, the whole data are analyzed, and the personality pattern is estimated in a comprehensive manner. In Japan, typical method includes Tokyo University Egogram (TEG), which is broadly popular and also used for its modified method [8]. As mentioned above, the theory of egogram and transactional analysis have been beneficial for many people. Because it is concerned with the attitude of life and the stance on life, and the relationship between you and other people is crucial. There are some check points for long life in each person as follows; what kind of basic life attitude / stance do you have, what kind of basic position you stand, how do you repeat to confirm matter.

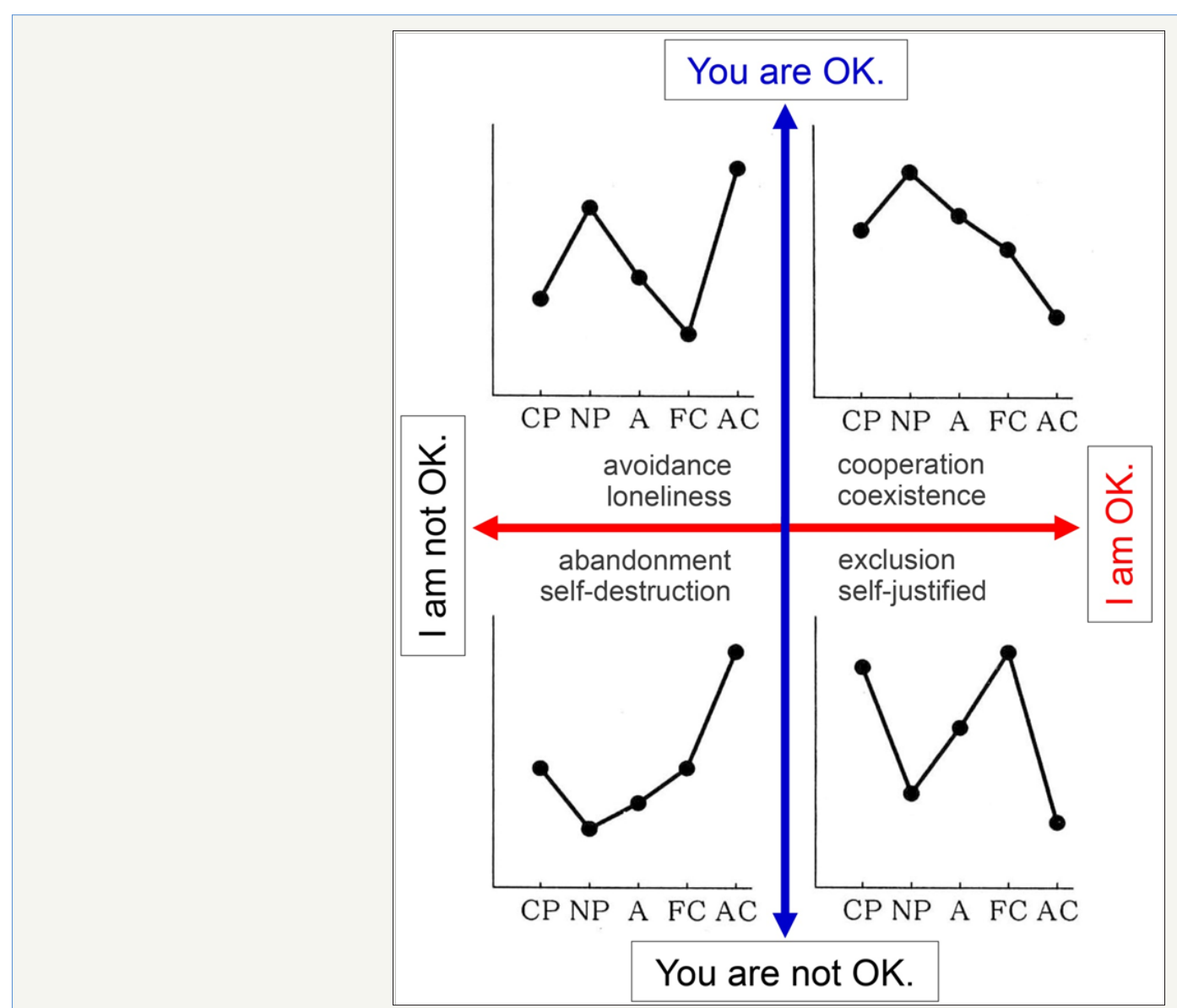

Figure 1 : Four types of relationship between the person and other people. In the light of transactional analysis, there are two axes of I am OK and You are OK.

Actually, there are four patterns how to judge and make a conclusion concerning how to deal with other people (Figure 1). Regarding life attitude or life stance, it is said to be formed at about 7 years old. The factor would be determined not from person's thinking ability, but from the environment brought up before obtaining thinking ability. The general information and background of 4 types were in the following [9].
1. A child was brought up in an environment that tends to accept him and the difference with others.

2. When a child worries, regrets or humbles, parents often tended to admit him.

3. When a child became irritated, lost his temper, or attacked the others, parents tended to acknowledge his existence. 
4. A child may have the experience and environment where he was neglected or not respected as a human.

After growing up and becoming an adult, it is important to notice the attitude and stance of the way of thinking. It is also possible to change the way of thinking himself. In such case, there is a tendency to change the process for improvement in the order of 4)-3)-2)-1) $[10,11]$. In summary, transactional analysis and egogram are useful in the field of psychology and psychosomatic medicine. Each person understands his own personality tendency, and the relationship with the surrounding people becomes better. Consequently, it will be expected for people to lead to smoother and happier long lives.

\section{References}

1. Berne E (1978) Transactional analysis. Ballantine Books, New York, USA

2. Dusay J (1977) Egograms - How I see you and you see me. Harper \& Row, New York, USA.

3. Saito H, Kimura Y, Tashima S, Takao N, Nakagawa A, et al. (2009) Psychological factors that promote behavior modification by obese patients. Biopsychosoc Med 3: 9.
4. Yoshioka A, Bando H, Yoshioka T (2004) Effect of musical experience on optimization of egogram. Jap J Music Ther 4(2): 191-197.

5. Nakao M, Kumano H, Nomura S, Kuboki T, Murata K (1999) Assessment of ego state in anorexia nervosa and bulimia nervosa. Acta Psychiatr Scand 99(5): 385-387.

6. Yanagihara K, Kinugasa Y, Shirota K, Inoue Y, Ishii H, et al. (2016) Child ego state is associated with high prevalence of repeated hospitalizations in patients with heart failure. ESC Heart Fail 3(1): 18-25.

7. Cai L, Kaneko S, Morita E (2018) Changes in salivary chromogranin A levels in adults with atopic dermatitis are correlated with changes in their condition. J Dermatol 45(5): 554-559.

8. Kuboki T, Nomura S, Wada M, Akabayashi A, Nagataki M, et al. (1993) Multidimensional assessment of mental state in occupational health care--combined application of three questionnaires: Tokyo University Egogram (TEG), Time Structuring Scale (TSS), and Profile of Mood States (POMS). Environ Res 61(2): 285-298.

9. Harris T (2004) I'm OK--You're OK. Harper Pernnial, New York, USA.

10. Steiner CM (1990) Scripts People Live: Transactional Analysis of Life Scripts. Grove Pr, New York, USA.

11. Berne E (2015) Transactional Analysis in Psychotherapy: A Systematic Individual and Social Psychiatry. Martino Fine Books, Eastford, USA.
Creative Commons Attribution 4.0 International License

For possible submissions Click Here

\begin{tabular}{|c|c|c|}
\hline PPRS & $\begin{array}{l}\text { Psychology and } \\
\text { Psyshothererpy: } \\
\text { Research Studuy }\end{array}$ & $\begin{array}{l}\text { Psychol Psychother Res Stud } \\
\text { Benefits of Publishing with us } \\
\text { - High-level peer review and editorial services } \\
\text { - Freely accessible online immediately upon publication } \\
\text { - Authors retain the copyright to their work } \\
\text { - Licensing it under a Creative Commons license } \\
\text { - Visibility through different online platforms }\end{array}$ \\
\hline
\end{tabular}

